\title{
Study on Shipment Consolidation in the Environment of Supply Chain Integration
}

\author{
June Liu ${ }^{\mathrm{a}}$, Lingyun Ding ${ }^{\mathrm{b}}$, Yuanming Dong \& Huaixu Yan \\ Beijing Wuzi University, Beijing 101149, China \\ ${ }^{a}$ Corresponding author \\ ${ }^{b}$ Corresponding author
}

\begin{abstract}
This paper is aimed at studying the mode of shipment consolidation in the environment of supply chain integration management. It briefly introduces the connotation of supply chain integration and shipment consolidation and three methods to realize it. Three kinds of typical policy of shipment consolidation are described in this paper, quantity-based policy (QP), time-based policy (TP), and hybrid policy (HP). The result of this paper is that the shipment consolidation can be well applied in logistics system. KEYWORD: supply chain integration; shipment consolidation; method; policy
\end{abstract}

\section{INSTRUCTIONS}

Transportation is an important part of the logistics system. Economic and reliable mode of transport has a significant impact on the entire logistics system. Due to the rapid development of information technology, the concept of supply chain integration management emerged, and supply chain logistics mode will also change. Low-cost, high-quality logistics services innovation will be gradually recognized. In the actual operation of the process of logistics, shipment consolidation appears, to improve transport efficiency and reduce transportation costs, which plays an important role in the entire supply chain optimization.

\section{THE CONNOTATION OF SUPPLY CHAIN INTEGRATION AND SHIPMENT CONSOLIDATION}

\subsection{Supply chain integration}

The general concept of an integrated supply chain is often illustrated by a line diagram that links participating firms into a coordinated competitive unit. The context of an integrated supply chain is multiform collaboration within a framework of key resource flows and constraints [1].

The dilemma supply chain managers face is that frequent deliveries from the suppliers to the buyer reduce inventory carrying cost, but they result in high transportation cost. Thus, if the cost of delivering products from a supplier to the buyer is high, the supplier has to ship large quantities to reduce the overall number of shipments in a cycle, which leads to high inventory carrying cost for both suppliers and buyers [2]. From the perspective of supply chain integration, to ensure that inventory costs and transportation costs are minimized, shipment consolidation applied in logistics system.

\subsection{Shipment consolidation}

Transportation cost is one of the most significant logistical costs, which almost accounts for the proportion of 50\%-60\%. Many logistical systems that feature direct fulfillment depend on high-speed, small-shipment transportation are costly, because transportation cost is directly related to the type of product, size of shipment, and movement distance. Thus, a system objective is to achieve shipment consolidation in order to reduce transportation cost. As a general rule, the larger a shipment and the longer distance it is transported, the lower is the cost per unit. Consolidation requires innovative programs to combine small shipments for timely consolidated movement. Such programs require multiform coordination because they transcend the supply chain.

The traditional approach of shipment consolidation is combining the goods or packages of Less Truck Loading (LTL) of the same destination together [3]. Products are transported from suppliers to manufacturers, distributors and retailers, and finally to customers with the help of the mode of consolidation shipment, to reduce costs and improve efficiency. The transport in the supply chain should ensure that it will require customer needs which is 
efficient, timely, accurate, economical and safe at all levels in the supply chain.

Shipment consolidation is one of the tools used to reduce transportation cost by utilizing the economies of scale in transportation [4]. Compared with first come first service (FCFS), shipment consolidation can effectively eliminate no-load, detour and a series of other cost and efficiency problems in transportation.

\section{THREE METHODS OF SHIPMENT CONSOLIDATION}

The aim of this work is to study shipment consolidation in a multi-vendor-multi -buyer integrated system. In this system, providers have access to real time point-of-sale data of customers, and they have a good knowledge of customer storage strategy and order policy, and maintaining good relationships with suppliers and customers. Shipment consolidation is carried out mainly in 3 types as follows [5].

\subsection{Appling the milk-run mode in goods collection or delivery}

Milk-run logistics is a generic name of a logistics procurement method that uses routing to consolidate goods by the buyer. It is a method of goods collection in which the user dispatches one truck at a specified time period to visit various suppliers following a predefined route to collect parts or products, and deliver them to the factory [6].

Milk-run mode can be used in shipment consolidation if vender group or customer group is made up of small entities whose distribution is concentrated. A truck picks up goods from several fixed suppliers and delivers goods to fixed users following a predefined route. Goods collection process is shown in Figure. 1 and delivery process is shown in Figure.2.
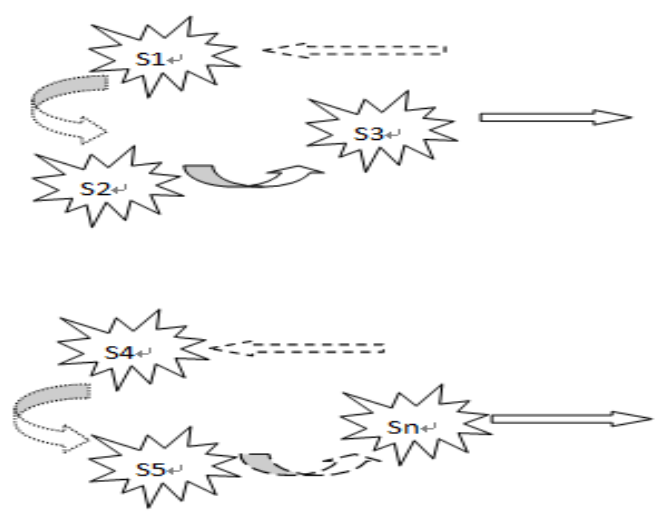

Figure.1. collection process of vender group

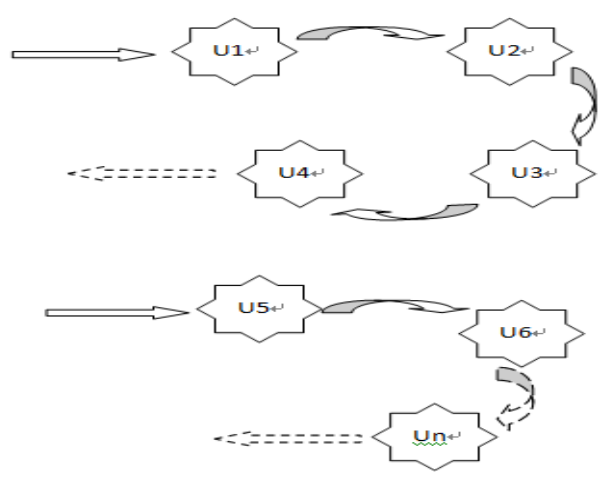

Figure.2. delivery process of customer group

\subsection{All goods through the distribution center}

Distribution center (DC) is defined as a place similar to a transportation organizational center, where goods from various origins are grouped or split, and is located at nodal point in the logistics system. All suppliers of goods should be delivered to DC, and then shipped to retail stores, not directly to the retail stores [7]. Compared with the milk-run mode, this mode is suitable for the situation when customer demand is multi-category, small batch, unstable supply and demand. As it has a role of temporary storing and distributing goods to customers, it can make the supply chain flexibility, adjust unmatched supply and demand, and improve customer satisfaction. The mode is shown in Figure.3.

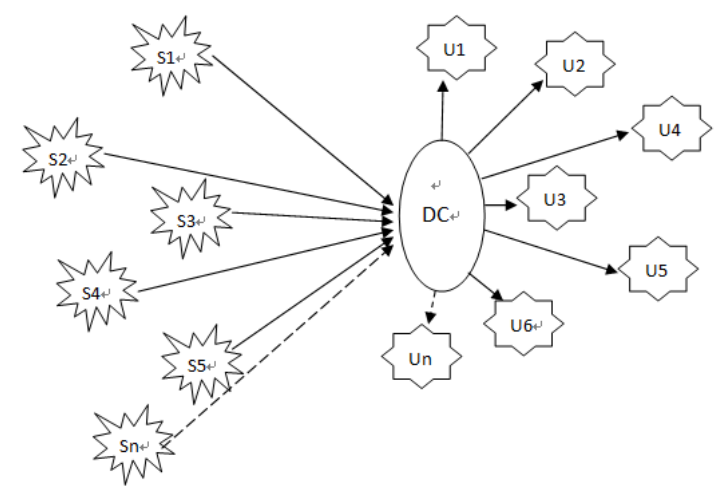

Figure.3.The mode of all goods through the distribution center

The characteristics of DC are multi-category, small shipment and multi-users. It promotes effective cooperation between the suppliers and customers. With the help of information technology, DC can function well, which can reduce the total transportation distance and costs.

\subsection{The combination of distribution center and milk-run}

This mode is the combination of DC and milk-run in the process of actual operation. The specific methods are determined by several variables such as types of goods, scale of shipment, update speed of inventory etc. There are three kinds of types in this mode. Under the first, supplier group pick up goods 
according to the mode of milk-run, then transport to the DC, finally deliver to each customer separately; Under the second, supplier group transport goods directly to the DC, and then the goods was delivered to customers in milk-run pattern; Under the third, supplier group collect and deliver goods according to the mode of milk-run. The three kinds of types are shown in Figure.4, Figure.5 and Figure.6. The combination of DC and milk-run is designed to produce economies of scale, as well as improve customer satisfaction.

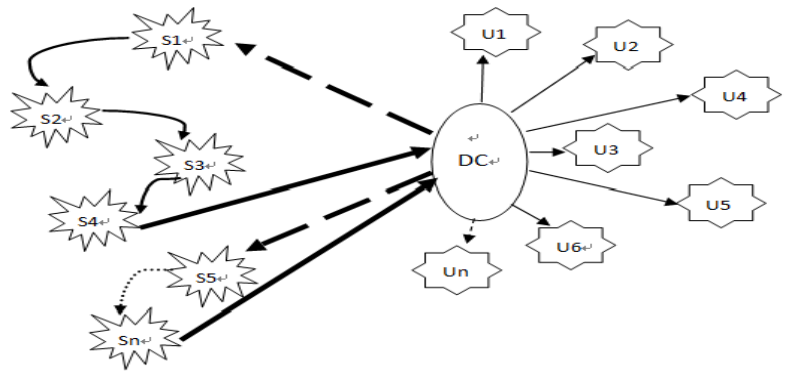

Figure.4. milk-run mode in collection process

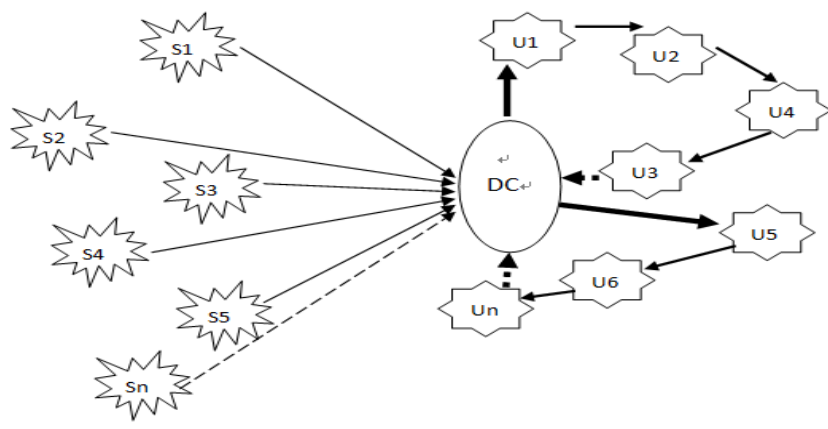

Figure.5. milk-run mode in delivery process

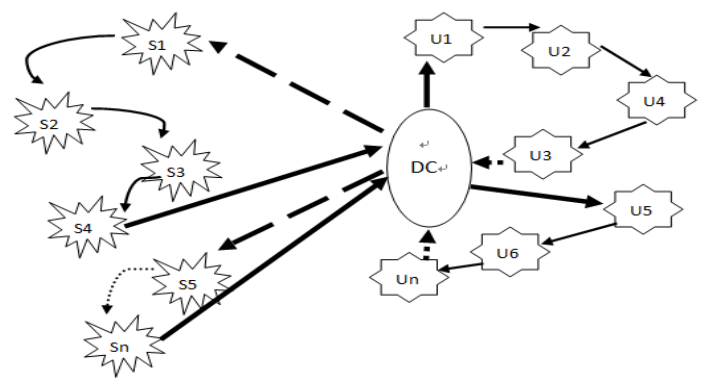

Figure.6. milk-run mode in collection and delivery process

\section{THREE CLASSICAL POLICIES OF SHIPMENT CONSOLIDATION}

This work is to study shipment consolidation in a multi-vendor-multi -buyer integrated system. In this model, suppliers have access to real time point-ofsale data of customers, and have a good knowledge of customer storage strategy and order policy. This paper abandons the simple FCFS policy, instead of using a postponement strategy based on advanced information technology ${ }^{[8]}$. This strategy can be well applied in shipment consolidation. There are three classical policies: quantity-based policy $(\mathrm{QP})$, time- based policy (TP), and hybrid policy (HP).

The primary reference standard of the shipment decision making of QP is the freight volume. The QP is aimed at consolidating a load of $\mathrm{q}$ units before releasing a shipment. The object is to consolidate a load of size $\mathrm{q}$ which is determined to produce good economic benefit. It would not release a shipment until the load reaches q. The procedure can be described as Figure.7.

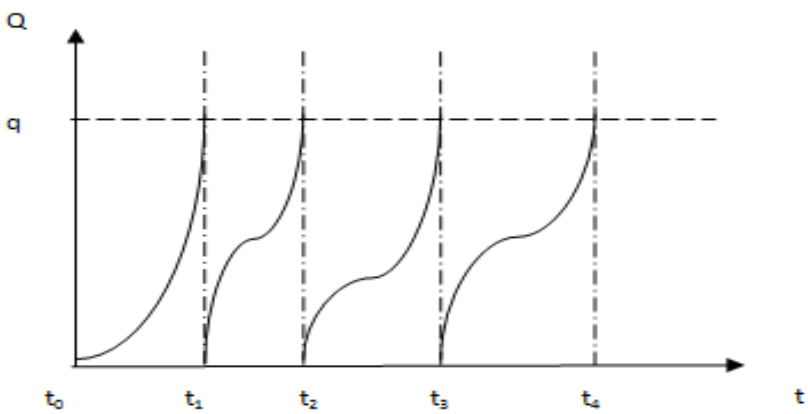

Figure.7. delivery strategy of QP

Note: ti $(\mathrm{i}=0,1,2 \ldots \ldots)$ is delivery time, and $\mathrm{q}$ is consolidation load. The curves describe function which symbol the accumulation of orders

There are two types of TPs, whose primary reference standard of the shipment decision making is time. Under the first, called TP1, a shipment is made every $\mathrm{T}$ units of time, and all orders that arrive between the two shipment epochs are consolidated. Under the other, called TP2, the arrival time of the first order after a shipment is recorded, and the next shipment is made $\mathrm{T}$ time units after the arrival time of the first order ${ }^{[9]}$. The procedure can be described as Figure.8 and Figure.9.

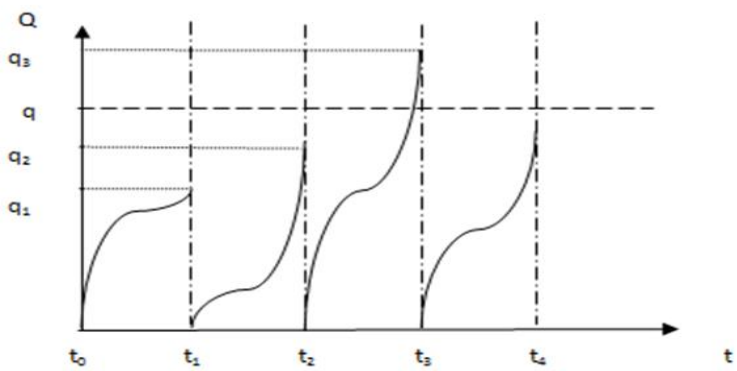

Figure.8. delivery strategy of TP1

Note: $\mathrm{ti}+1-\mathrm{ti}=\mathrm{T}$, qi $(\mathrm{i}=0,1,2 \ldots \ldots)$ indicates the load size of a shipment

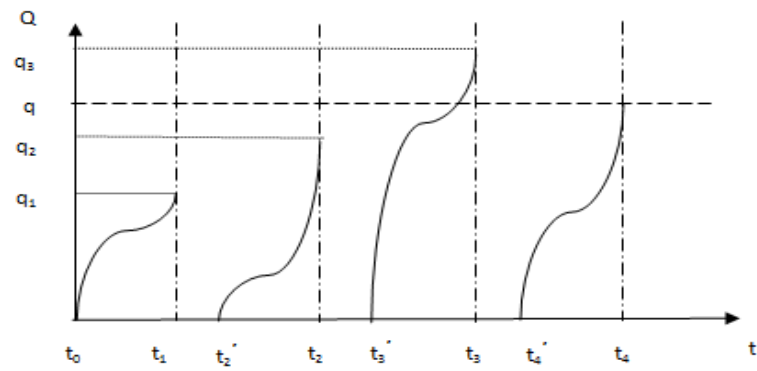

Figure.9. delivery strategy of TP2

Note: $\mathrm{ti}-\mathrm{ti}=\mathrm{T}$, ti' indicates the arrival time of the first order after a shipment is recorded 
There are two types of HPs. The first is a combination of QP and TP1, called HP1, and the second is a combination of QP and TP2, called HP2. Under HP1, the goal is to consolidate a load of size q. However, if the time since the last shipment epoch exceeds $\mathrm{T}$, then a shipment decision is made. Under HP2, the goal is also to consolidate a load of size q; but, if the waiting time of the first order after the last shipment exceeds $\mathrm{T}$, then a shipment decision is made. The procedure can be described as Figure.10 and Figure.11.

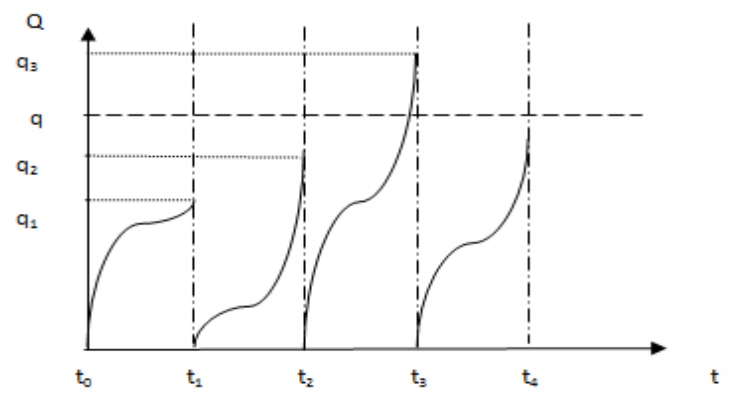

Figure.10. delivery strategy of HP1

Note: a shipment decision is made when $\mathrm{t} i+1-\mathrm{t}=\mathrm{T}$ or $\mathrm{q} i=\mathrm{q}$

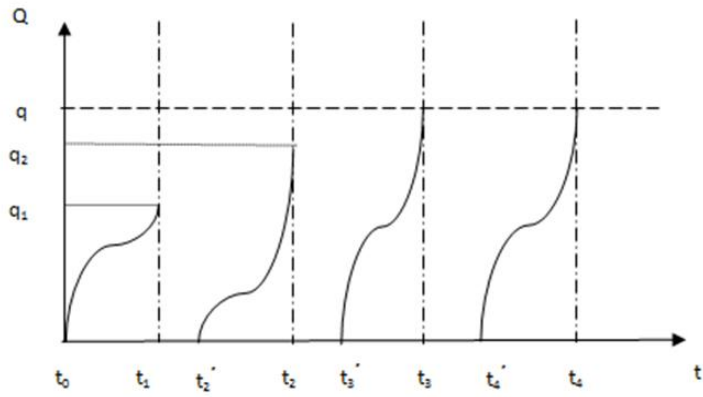

Figure.11. delivery strategy of HP2

Note: a shipment decision is made when $\mathrm{ti}-\mathrm{ti}^{\prime}=\mathrm{T}$ or $\mathrm{qi}=\mathrm{q}$

The policies are implemented at the cost of prolonged order holding, hence, customer waiting due to delayed delivery associated with the time needed to accumulate a large load [10]. The resulting service performances are strongly interrelated with the corresponding waiting times which need to be considered carefully for all practical purposes.

The three classical policies above are well applied in logistics system. Different policies are used in different practical situations, in order to forming scale effect, and reducing logistics costs. However, it all depends on the realities of suppliers and users when using them.

\section{CONCLUSIONS}

21 st century is an individual era, with the development of e-commerce, multi-category, small shipment and remote distribution are major characteristics of the customer demand. However, it brings great challenge to the logistics operation. Shipment consolidation is applied in logistics system in the environment of supply chain integration, which makes benefit to the entire system. The essence of shipment consolidation is reducing the operation cost through the scale operation, and improving the utilization efficiency of logistics resources. Compared with the traditional transport, shipment consolidation makes a significant contribution to improve the economic efficiency, social benefits, and the development of green logistics.

\section{ACKNOWLEDGEMENTS}

This work was financially supported by the Research on Key Technologies of Business Intelligence in the Context of Big Data, which was one of key projects of Beijing Wuzi University.

\section{REFERENCES}

[1] Donald J. Bowersox, David J. Closs \& M. Bixby Cooper. 2009. Supply Chain Logistics Management,3rd Edition. Beijing: Machine Press.

[2] Christoph H. Glock \& Taebok Kim. 2014. Shipment consolidation in a multiple-vendor-single-buyer integrated inventory model. Computers \& Industrial Engineering (70):31-42.

[3] Xiangqian An \& Ruixiu Jia.2012. study on the mode of shipment consolidation. Shang Qing 12(8):209.

[4] Ismail Capar. 2013. Joint shipment consolidation and inventory decisions in a two-stage distribution system. Computers \& Industrial Engineering 13(66):1025-1035.

[5] Xiaojuan Feng \& lide Hu. 2007. Research on Milk- run Transport Technology and Method under SC. Logistics Technology 26(2):148-150.

[6] Toshinori Nemoto, Katsuhiko Hayashi \& Masataka Hashimoto. 2010. Milk-Run logistics by Japanese automobile manufacturers in Thailand. Procedia Social and Behavioral Sciences 10(2):5980-5989.

[7] S.H. Chung, H.K. Chan \& F.T.S. Chan. 2014. A modified genetic algorithm for maximizing handling reliability and recyclability of distribution centers modified genetic algorithm for maximizing handling reliability and recyclability of distribution centers. Computers \& Industrial Engineering 14(70):31-42.

[8] Christian Howard \& Johan Marklund. 2011. Evaluation of stock allocation policies in a divergent inventory system with shipment consolidation. European Journal of Operational Research 11(211):298-309.

[9] Sila, Cetinkaya, Fatih Mutlu \& Bo Wei. 2014. On the service performance of alternative shipment consolidation policies. Operations Research Letters 14(42):41-47.

[10] M. Ali Ulku \& James H. Bookbinder. 2012. Optimal quoting of delivery time by a third party logistics provider: The impact of shipment consolidation and temporal pricing schemes. European Journal of Operational Research 12(221):110-117. 